\title{
Effect of particle breakage on the shear strength of calcareous sands
}

\author{
Houzhen Wei ${ }^{1} \cdot$ Mei Yin ${ }^{2}$ (]) $\cdot$ Tao Zhao $^{2} \cdot \mathrm{Ke} \mathrm{Yan}^{1} \cdot$ Jianhua Shen $^{1} \cdot$ Qingshan Meng ${ }^{1} \cdot$ Xinzhi Wang $^{1} \cdot$ Jianqiao He $^{3}$
}

Received: 20 August 2020 / Accepted: 9 June 2021 / Published online: 4 July 2021

(c) The Author(s) 2021

\begin{abstract}
The particle breakage of calcareous sands plays a key role in determining the particle shape and shear strength. This process has been analysed in the current study by employing the ring shear tests on calcareous sands sampled from the South China Sea. In this study, a set of parameters, e.g. roundness and aspect ratio, have been employed to quantify the geometrical properties of calcareous sands pre- and after the breakage. These two parameters have been found to correlate well with the vertical loading stress level, shear strain and shear strength. The particle breakage leads to the change of micro-structure during the shear test, as illustrated by the Scanning Electron Microscopy (SEM) images. It is found that during the shearing deformation, particle breakages can effectively reduce, while particle rearrangements can increase the shear strength of the calcareous sands.
\end{abstract}

Keywords Ring shear test $\cdot$ Calcareous sands $\cdot$ Particle breakage $\cdot$ Particle shape $\cdot$ Shear strength

\section{Introduction}

Calcareous sands can be widely observed in tropical marine environment. The intrinsic properties distinguish calcareous sands from other terrigenous sediments both physically and mechanically, in terms of particle angularity, high crushability, and weakly cemented soil structure (Wang et al. 2017). As stated by Coop and Atkinson (1993), calcareous sands tend to have very loose fabric, due to particle interlocking effect and extremely high intra-granular void ratios. However, the mechanical performance of calcareous sands, in particular the effect of particle breakage and their shear strength, are poorly understood. On the other hand, an increasing number of offshore engineering practices where calcareous sands proliferate have promoted the necessity of comprehensive studies on this aspect (Xu et al. 2020c).

Mei Yin

Mei.Yin@brunel.ac.uk

1 State Key Laboratory of Geomechanics and Geotechnical Engineering, Institute of Rock and Soil Mechanics, Chinese Academy of Sciences, Wuhan 430071, China

2 Department of Civil and Environmental Engineering, College of Engineering, Brunel University London, Uxbridge, UK

3 Guangxi Road and Bridge Engineering Group Co., Ltd, Nanning 530011, China
The material composition (e.g. mainly calcium carbonate of low hardness) together with particle morphology such as angularity, surface roughness, as an inherent feature of soil have significant influence on its mechanical and geological properties (e.g. shear strength, dilatancy and crushability). Owing to these unique properties, calcareous sands can be fragmented readily under even relatively low loading stress (Wei et al. 2018). This phenomenon has been recognized as one of the most important features of calcareous sands, which is closely related to the strength, deformation and permeability of calcareous sands (David et al. 2011; Shahnazari and Rezvani 2013). In fact, the dynamic breakage of calcareous sands has been widely observed in some engineering practices (Coop et al. 2004, Fukuoka et al. 2007, Hardin 1985, Hyodo et al. 2002, Lade et al. 1996, Miao and Airey 2013, Pfleiderer et al. 2006, Wu et al. 2014, Yu 2017, $\mathrm{Xu}$ et al. 2020a). It usually occurs when the shear stress exceeds the shear strength of sands, especially for the poorly graded samples (Bolton et al. 2008). By conducting a series of 1D compression tests, Altuhafi and Coop (2011) found that very limited breakages occurred in very well-graded samples, while a significant amount of particle breakages occurred in uniformly graded samples. Einav (2007) also observed similar results, and they explained that the coarse particles are more resistive to crushing because the surrounding fine grains could provide cushions. However, this conclusion contradicts the generally accepted idea that the 
shear strength increases with decreasing particle size (Hardin 1985). This is because the forces transferring at contacts are dominant for dense granular packing, and the potential defects within the solids could be neglected. In addition, Altuhafi and Coop (2011) observed that the angular particle shape tends to evolve towards spherical and median surface roughness, with much lower aspect ratios than the original particles after breakage. As discussed in Zhang et al. (2015), the breakage pattern of initially non-uniformly graded particles can be considered as a collection of uniformly graded particles with the crushing state of each particle size group following the Weibull distribution. Kong and Fonseca (2018) claimed that the particle breakage is a required 'unlocking' mechanism for calcareous sands, so that grain slippage and rotation can be achieved. As a result, the soil fabric can evolve into a more compacted packing state.

Although lots of research have been performed to investigate the particle shape characteristics and the potential influence on soil shear strength under various testing conditions, quantitative analyses of particle breakage and the corresponding micro-structure changes are still very limited. These limitations prompt this experiment research on calcareous sands, with the purpose to demonstrate the effect of particle breakage on shear strength evolution in ring shear tests, as presented herein. This paper is organized as follows: firstly, the experimental testing methods are given. Then, the analyses of experimental data are presented, with respect to particle shape and shear strength variations during shearing. The final section summarizes major conclusions reached in this study.

\section{Experimental description}

This study follows the research by Wei et al. (2018), employing the ring shear tests to investigate the mechanical and deformation behaviour of calcareous sands sampled from Yongshu Coral Reef, South China Sea. Different from previous study, this investigation was based on the quantification of dynamic particle breakage during the ring shear tests for calcareous sands. Two series of tests were performed using the ring shear device DTA-138 (shown in Fig. 1) to investigate the evolution of particle breakage and its effect on the shear strength of calcareous sands. In these tests, the consolidated and drained (CD) conditions were employed to reproduce the stress state of soil during pile driving process at relatively high shear speeds. The sample with the minimum dry density of $1.03 \mathrm{~g} / \mathrm{cm}^{3}$, and the initial void ratio of 1.71 was placed in a shear box. The outer diameter, inner diameter and height of the shear box were $150 \mathrm{~mm}$, $100 \mathrm{~mm}$ and $20 \mathrm{~mm}$, respectively. After the calcareous sand specimens was sieved, the uniformly graded sand sample with initial size range $0.5-1 \mathrm{~mm}$ was chosen and placed in

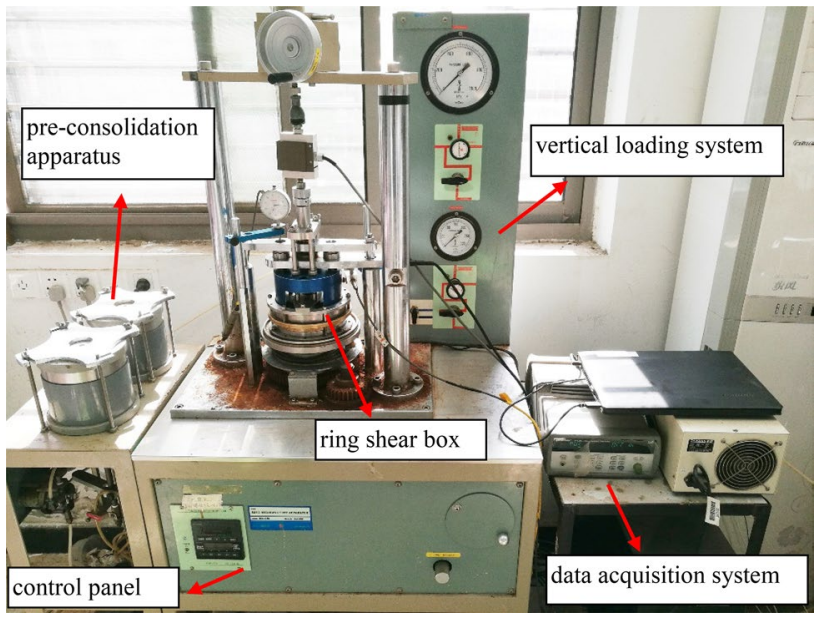

Fig. 1 Ring shear test apparatus

the shear box. The strain rate of all shear tests was kept as a constant of $2.18 \mathrm{~min}^{-1}$. In the first series of tests, the vertical loading stress varied from 50 to $600 \mathrm{kPa}$, while the final shear strain kept constant as $2500 \%$. In the second series of tests, the vertical loading stress was kept as $400 \mathrm{kPa}$, but the final shear strain varied from 125 to $5000 \%$ to investigate the variation of particle shape factor with the shear strain. The details of the ring shear test can be found in Wei et al. (2018). In order to quantify the shape characteristics of sand particles, a set of image processing procedures were used after each test, described as below:

(a) After each ring shear test, calcareous sand in the shear band were retrieved carefully from the testing platform. These sands were washed by distilled water and dried in an oven with the temperature of $95^{\circ} \mathrm{C}$ for $24 \mathrm{~h}$.

(b) Calcareous sands were sieved. For each size range including $[0.075,0.1] \mathrm{mm},[0.1,0.15] \mathrm{mm},[0.15,0.25]$ $\mathrm{mm},[0.25,0.5] \mathrm{mm}$ and $[0.5,1] \mathrm{mm}, 100$ soil particles were randomly selected for shape analysis.

(c) The light microscope was used to obtain the two dimensional (2D) projected particle images, as shown in Fig. 2. These images were converted to the grayscale image, so that it could be digitized for the further analysis by IPP (Image Pro plus).

(d) The image pixels were then converted to real particle dimensions which were then used to compute the fundamental geometric parameters, such as the contour's perimeter, area, maximum and minimum Feret diameters (Hentschel and Page 2003).

The Scanning Electron Microscopy (SEM) was employed to quantitatively analyse the information of soil particles in the shear tests (Cox and Budhu 2008). The magnification 
Fig. 2 An example of image analysis, a grayscale $2 \mathrm{D}$ projected grain image obtained via microscope; $\mathbf{b}$ the black-white image after the image binary progress
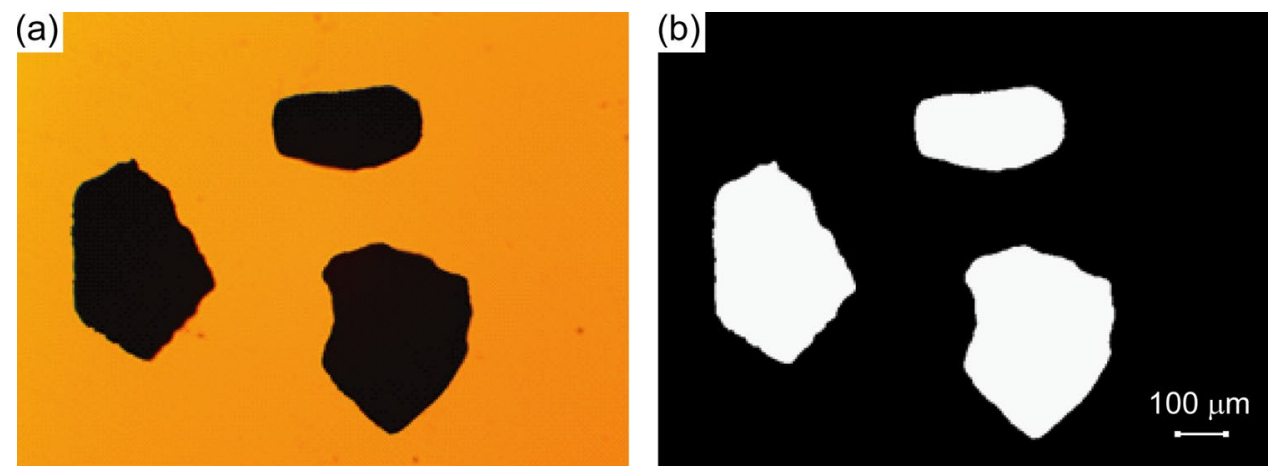

of SEM used in this study is about $\times 5000-\times 10000$, which was capable of identifying the particle profile and surface roughness with very high precision. The electrical conductivity was increased by gilding calcareous sands before the SEM scanning. After that, the grain images could be produced using SEM scanning. In order to quantify the grain shape characteristics based on the grain image, three key shape parameters have been defined, as shown in the Fig. 3, including:
Particle aspect ratio, $\quad e=\operatorname{Feret}(\max ) /$ Feret $(\min )$

Roundness, $\quad R=P^{2} /(4 \pi A)$

Sphericity, $\quad s=R_{i} / R_{c}$

where Feret (min) and Feret (max) denote the minimum and maximum Feret lengths measured at all possible particle
Fig. 3 Diagram of the definition of some key particle shape descriptors. The projected particle shape is shown as the grey region (modified after Merkus, 2009)

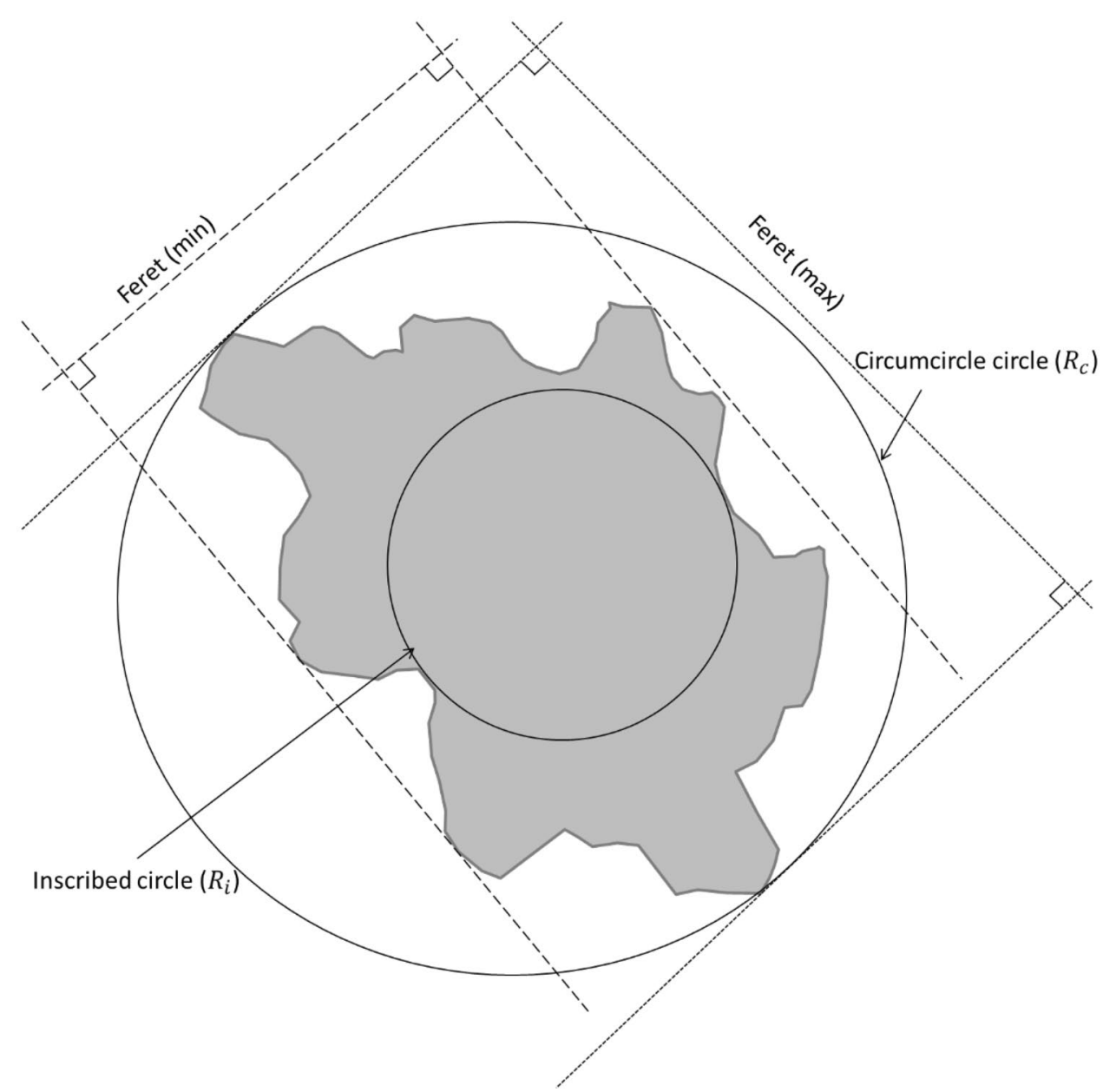


orientations; $P$ is the perimeter and $A$ is the projected area of the particle; $R_{i}$ and $R_{i}$ are radii of the corresponding inscribed circle and circumcircle, respectively.

At different shear strain during the test, sixty particles in each size range were randomly selected for image analysis by IPP (Image Pro plus) to calculate shape parameters. The roundness and aspect ratio for each particle were calculated, and then averaged by particle numbers. It should be noted that when the width and length of shape approach the same value, the particle aspect ratio approaches to 1 . It does not necessarily mean that the shape is circular though a circle does have an aspect ratio of 1.0 (Olson 2011). In terms of the roundness the value approaches 1 indicating more round and smooth shape.

\section{Results and discussions}

\section{Variation of particle shape under different vertical loading stresses}

Xu et al. (2020b) found the soil particles would influence the soil creep behaviour when the clay fraction over $30 \%$. Therefore, after each ring shear test, the particle size distribution of the sample has been investigated. For example, Fig. 4 presents the particle distribution of the sample with the initial particle sizes between 0.5 and $1 \mathrm{~mm}$ under different vertical loading stresses. It can be found that larger vertical stresses result in a more evenly spread of particle size as a smooth, concave particle-size distribution (PSD). Under the vertical stresses of $50 \mathrm{kPa}, 100 \mathrm{kPa}$, it's shown that about $80 \%$ of large particles with particle size larger than $0.2 \mathrm{~mm}$ remains after shearing. When the vertical stresses increase, more larger particles have been further sheared and broken into smaller particles. Hence, a more evenly spread of particle size was observed.

Figure 5 shows the shear stress under different normal loading stresses. It is shown that the shear stress increases sharply at the beginning of the shear test. It reaches the peak value at the shear strain of approximate $3 \%$, equivalent to the shear displacement of $12 \mathrm{~mm}$. Then, the shear stress reduces significantly with the shear strain. After that, further increase of shear strain only leads to a slow increase in the shear strength. All the final peak shear strength and strains corresponding to peak shear strength are listed in Table 1 .

The maximum shear strength of calcareous sands at different vertical loads is defined as the peak shear strength. After shear stresses reach peak values they drop significantly until approach residual shear strengths at the shear strain $\gamma \geq$ $25 \%$. Then a fluctuation in the shear stress can be observed which may indicate the intensive particle breakages and rearrangements developing in the shear band. This behaviour has also been observed by Wei et al. (2018). The shear strain $\gamma$ can be calculated as,

$\gamma=\delta h / C$

where $\delta h$ is the shear displacement; $C$ is the mean circumference of the specimen (Wei et al. 2018). In this study, the minimum shear strength at the shear strain $\gamma \geq 25 \%$ is assumed as ultimate residual strength.

These shear strengths have been plotted in Fig. 6. It is shown that all these three shear strengths exhibit a linear relationship with the normal stress. The peak strength is
Fig. 4 Particle size distribution under various vertical loading stresses

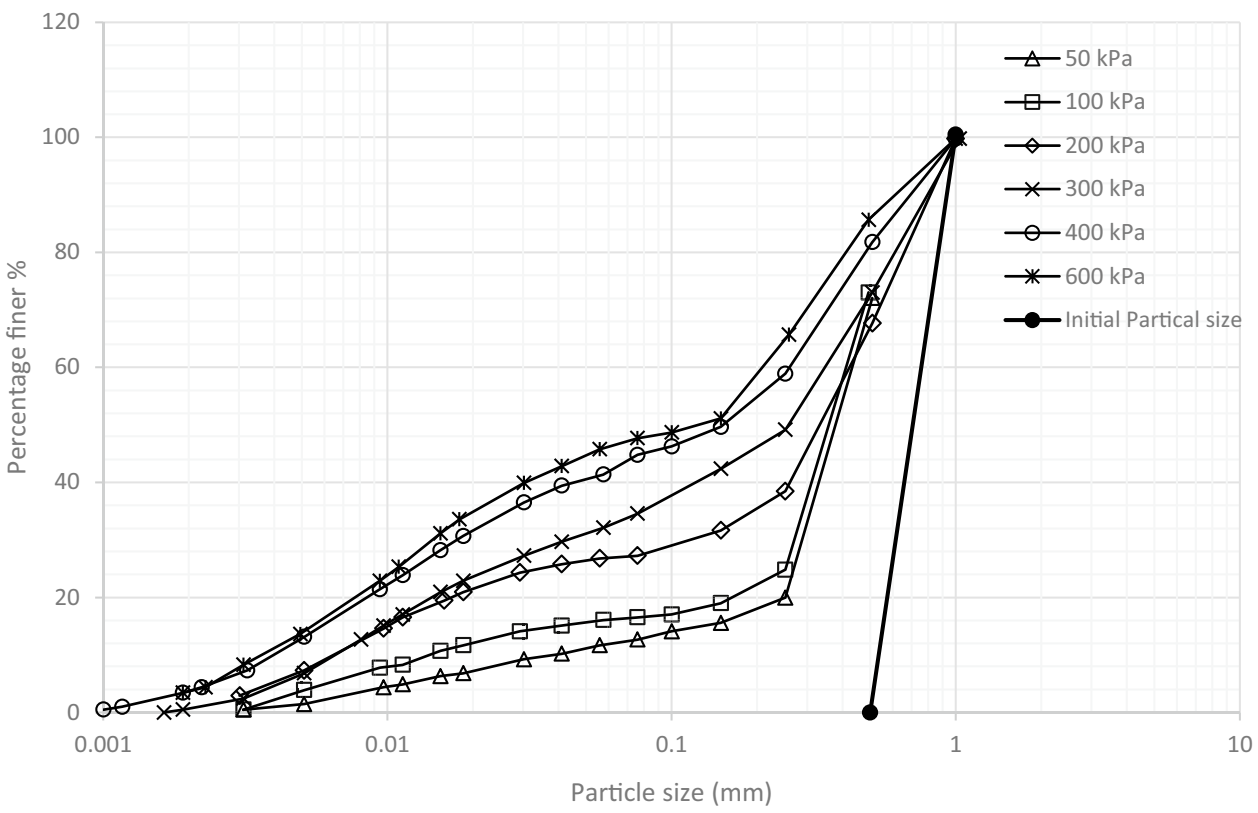


Fig. 5 Shear stress-strain curves Table 1. Details of the testing conditions

Table 1 Details of the testing conditions

Fig. 6 A summary of shear strengths for different loading stresses

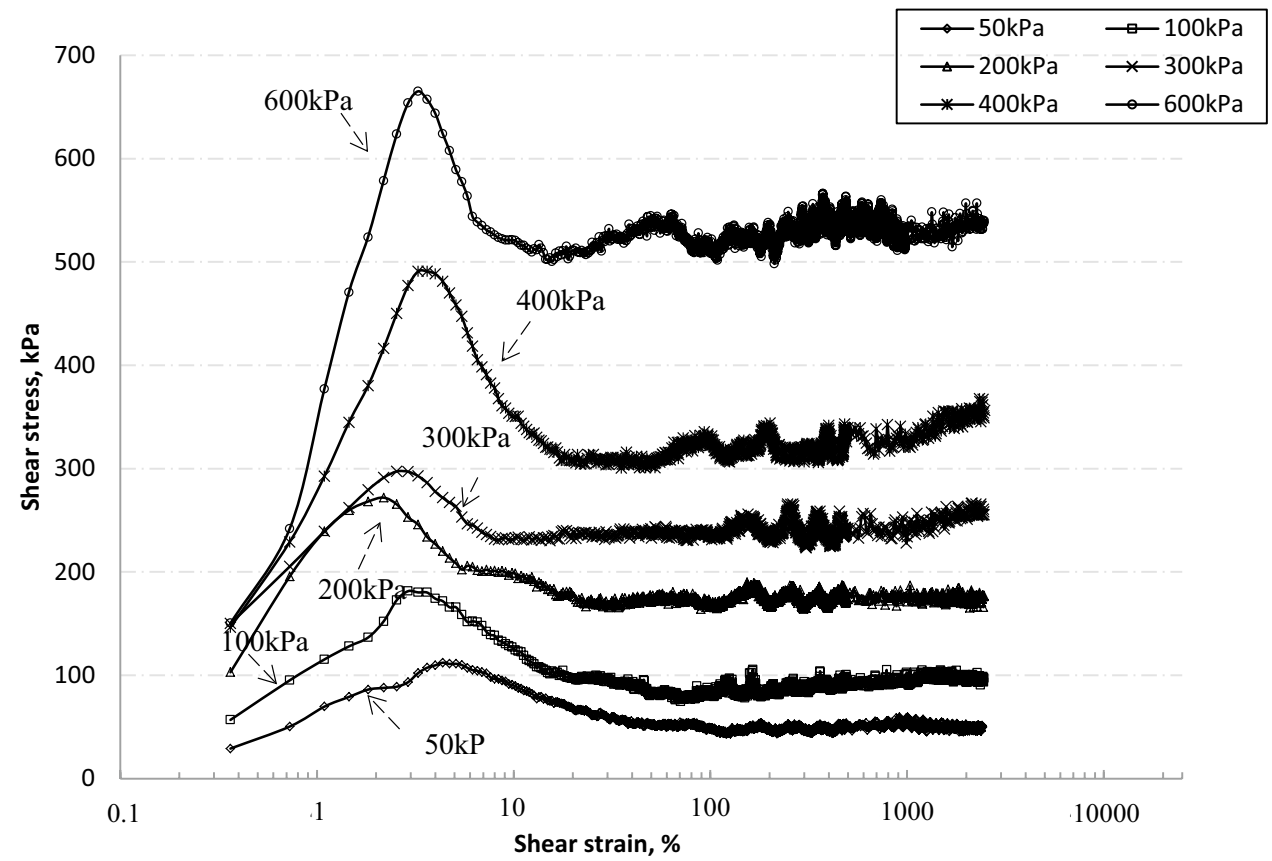

\begin{tabular}{lllllll}
\hline Test no. & $\begin{array}{l}\text { Initial } \\
\text { grading } \\
(\mathrm{mm})\end{array}$ & $\begin{array}{l}\text { Vertical } \\
\text { stress, } \sigma_{v}, \\
(\mathrm{kPa})\end{array}$ & $\begin{array}{l}\text { Shear strain } \\
\text { rate }\left(\mathrm{min}^{-1}\right)\end{array}$ & $\begin{array}{l}\text { Final shear } \\
\text { strain }(\%)\end{array}$ & $\begin{array}{l}\text { Peak shear } \\
\text { strength } \\
(\mathrm{kPa})\end{array}$ & $\begin{array}{l}\text { Strains corresponding to } \\
\text { peak shear strength }(\%)\end{array}$ \\
\hline RS 1 & $0.5-1$ & 50 & 2.18 & 2500 & 665.95 & 3.27 \\
RS 2 & $0.5-1$ & 100 & 2.18 & 2500 & 494.61 & 3.63 \\
RS 3 & $0.5-1$ & 200 & 2.18 & 2500 & 349.14 & 2.91 \\
RS 4 & $0.5-1$ & 300 & 2.18 & 2500 & 268.32 & 2.18 \\
RS 5 & $0.5-1$ & 400 & 2.18 & 2500 & 181.03 & 3.27 \\
RS 6 & $0.5-1$ & 600 & 2.18 & 2500 & 113.15 & 4.36 \\
\hline
\end{tabular}

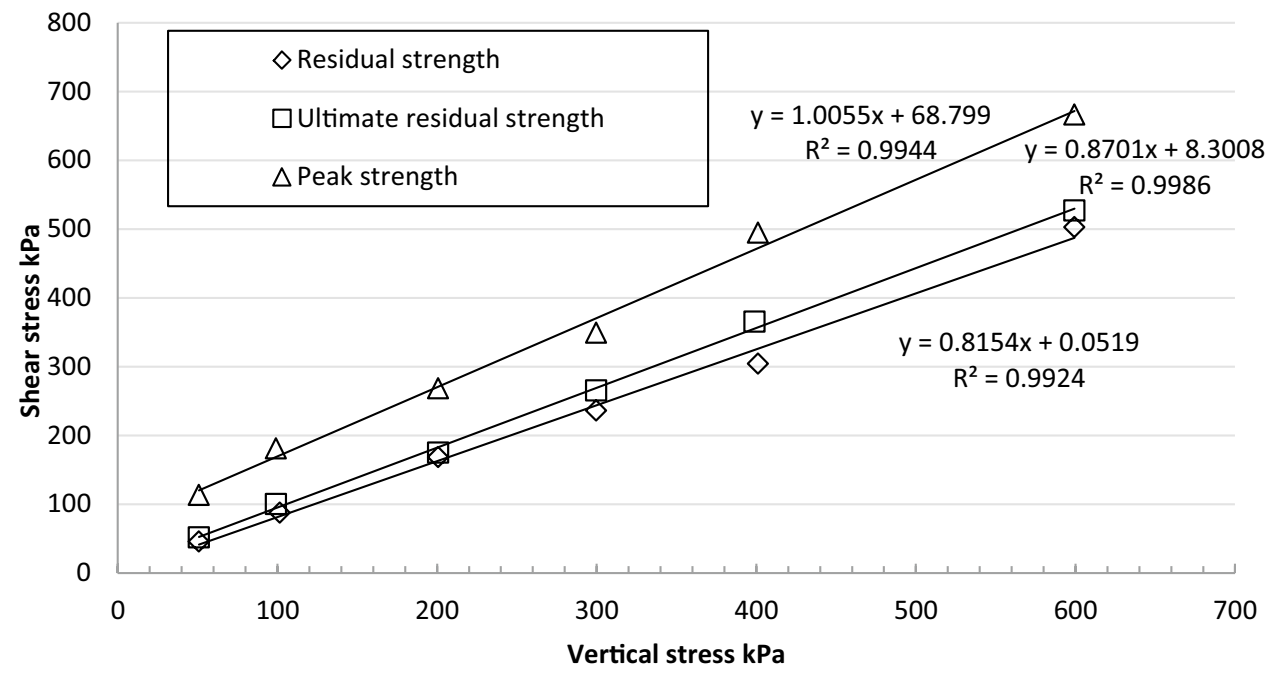


noticeably higher than the other two curves. On the other hand, the initial residual strength proceeds at a slightly slower rate than that for the final residual strength. This difference between initial and final residual strength is due to the effect of particle breakage during the ring shear test, which will be discussed in detail below. The shear strength $\tau$ can be calculated using the Mohr Coulomb failure criterion,

$\tau=c+\sigma \cdot \tan \varphi$

where $\varphi$ is the peak friction angle, $c$ is the interlocking induced shear strength considering calcareous sand as a cohesionless material. According to this equation, $c$ equals to $68.799 \mathrm{kPa}$ for peak strength. Then $c$ decreased to about $0.05 \mathrm{kPa}$ at the residual stage. As the shearing deformation increases, this shear strength due to particle interlocking increases slightly up to $8.82 \mathrm{kPa}$ for the final residual strength.

Figure 7 shows the roundness changes at the shear strain of $2500 \%$. The average roundness was about 1.39 under the vertical loading stress of $50 \mathrm{kPa}$ and 1.29 under the vertical loading stress of $400 \mathrm{kPa}$, which indicates that the average roundness decreased with the increasing vertical loading stress. Therefore, the shape of calcareous sand particles got more and more rounded during the shearing process. But when the vertical loading stress exceeded $400 \mathrm{kPa}$, the change of roundness became very limited. Under the vertical loading stress of $50 \mathrm{kPa}$, the average roundness of all calcareous sand samples was smaller than that of the sand samples $[0.25 \mathrm{~mm} 1 \mathrm{~mm}]$ and $[0.075 \mathrm{~mm} 0.1 \mathrm{~mm}]$, but larger than the samples $[0.1 \mathrm{~mm} 0.25 \mathrm{~mm}$ ]. This difference indicates the median size particles become more round during this shearing process, acting as the major rolling particles. When the loading stress increases to $100 \mathrm{kPa}$, the roundness of the sand samples $[0.1,0.15] \mathrm{mm}$ and $[0.15,0.25] \mathrm{mm}$ became larger than the average value. Meanwhile, the value of the sample [0.075 mm $0.1 \mathrm{~mm}]$ decreased significantly due to particle breakage, which indicates the fine particles acted as the major rolling particles to carry the shear stress. Under the $400 \mathrm{kPa}$ loading stress, the roundness of all samples was close to the average curve, except the coarse sample [ $\left.\begin{array}{ll}0.5 & 1.0\end{array}\right] \mathrm{mm}$. This result proves that the breakage process of coarse particles had not finished at the shear strain of $2500 \%$. These particles were cushioned by the fine particles, and hence avoided further breakage. Hence, it still showed a large roundness after long distance of shearing. On the other hand, when the vertical loading stress increased to $600 \mathrm{kPa}$, the roundness of all samples was close to the average value. This is due to the particle breakage process of all samples had finished, so all the calcareous sand samples showed similarly low values of roundness.

Figure 8 shows the aspect ratio changes at the shear strength of $2500 \%$. Under the vertical loading stress of $50 \mathrm{kPa}$, the aspect ratios of all samples except [0.1 0.15$]$ $\mathrm{mm}$ and $\left[\begin{array}{ll}0.15 & 0.25\end{array}\right] \mathrm{mm}$ were close to the average. This was probably caused by the breakage of coarse particles, generating more particles with size ranging between 0.1 and $0.25 \mathrm{~mm}$. These new particles were formed due to shearing and breakage, so their shape showed more regular. With the loading stress increasing to $100 \mathrm{kPa}$, the aspect ratio of coarse particles [0.5 1.0$] \mathrm{mm}$ increased significantly, which showed marked difference from other samples. At the same time, the fine particles $[0.075 \mathrm{~mm} 0.1 \mathrm{~mm}$ ] showed a very low aspect ratio. Hence, these phenomena were due to the fine particles acting as a lubricating material after initial particle breakage. These fine particles cushioned the coarse particles from further breakage, which caused the large difference in aspect ratio between coarse and fine particles. On the other hand, when the loading stress kept increasing to $600 \mathrm{kPa}$, the aspect ratio of all the samples was near the average. This indicates that all calcareous sand particles
Fig. 7 Roundness changes under different vertical loading stresses for sand samples of different particle sizes

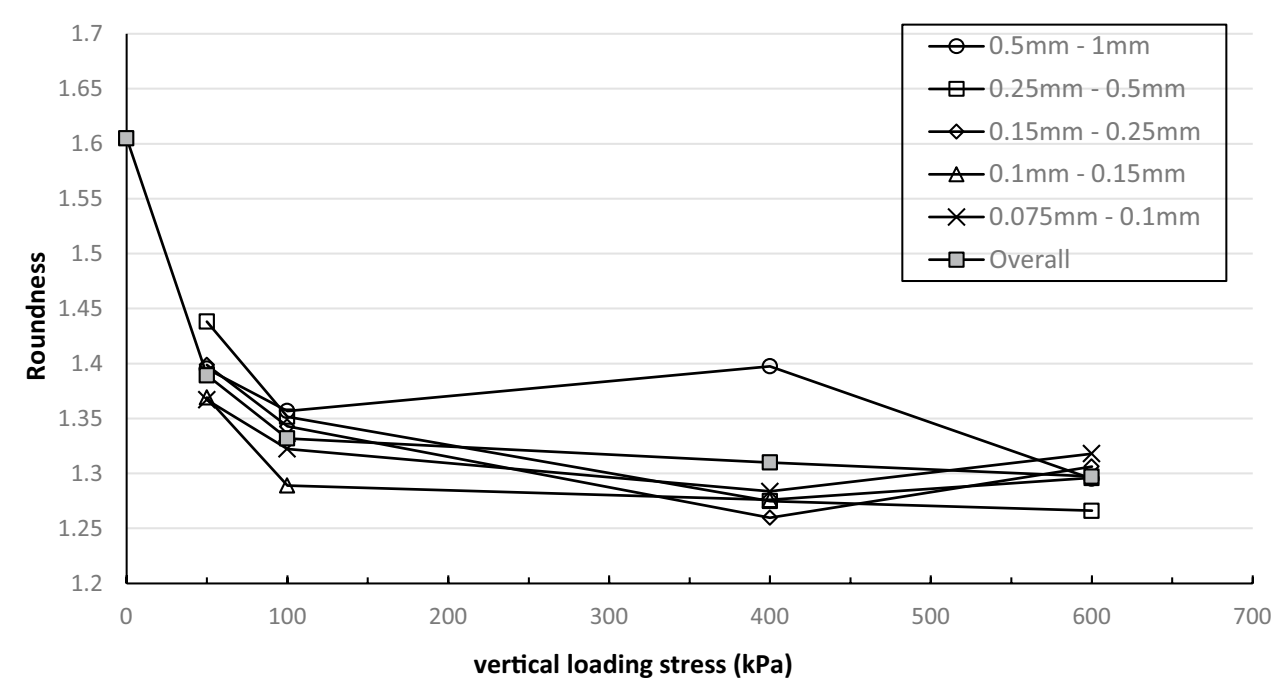


Fig. 8 Aspect ratio changes under different vertical loading stresses

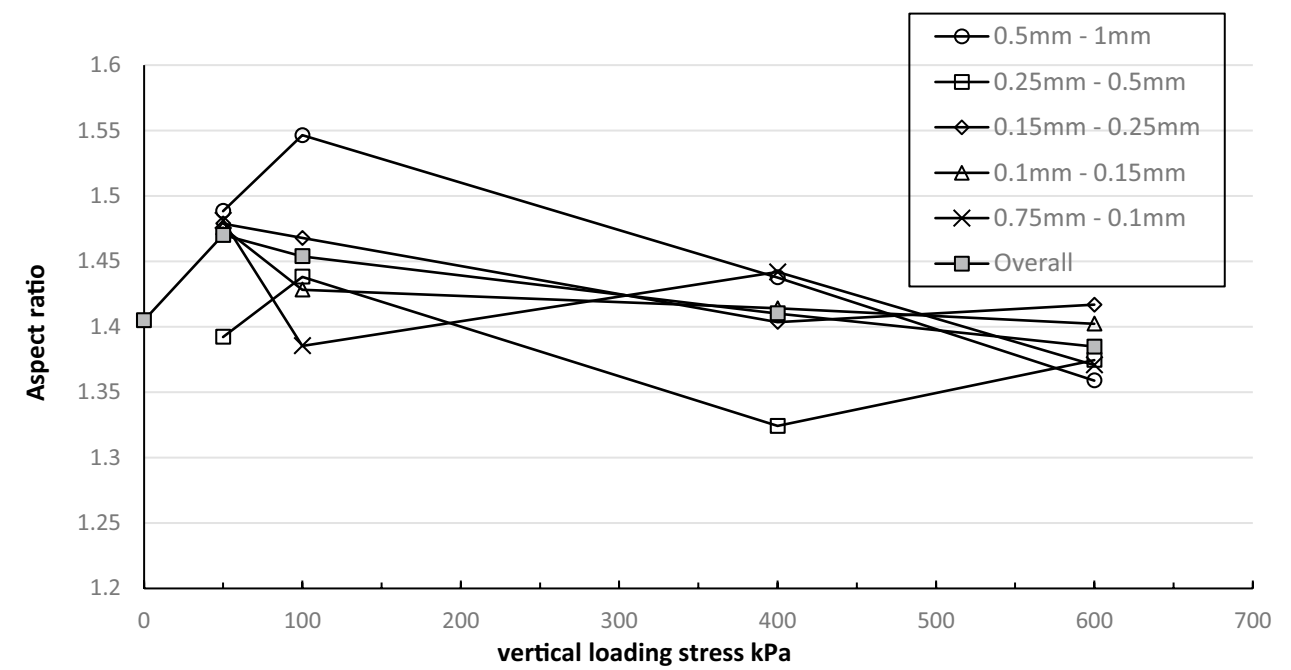

were fully broken and polished, and hence all the aspect ratios became very low.

\section{Variation of particle shape with different final shear strain}

In the second series of tests, Calcareous sand particles were retrieved from the shear band after each ring shear test at different shear strain. As an example, the variation of roundness and aspect ratio under vertical loading stress of $400 \mathrm{kPa}$ is shown in Figs. 9 and 10. The original overall values of the roundness and the aspect ratio of calcareous sands were approximate 1.6 and 1.5 , respectively. It can be seen that both the particle roundness and the aspect ratio decrease as the shear strain increases, indicating that the calcareous particles are gradually fragmented to become rounded in the shearing process. These two values became stable after the shear strain has exceeded $2500 \%$. The values of roundness and aspect ratio were constant about 1.3 and 1.4 respectively. This is probably due to very limited brakeage happened at this stage compared to previous stage. In addition, the average value decreases as well with increasing shear distance, which indicates that the whole granular system is evolving towards a homogeneous state, resulting in smooth and rounded particles.

Figure 11 shows an example of the residual shear strength at the certain shear strain $(125 \% \leq \gamma \leq 5000 \%)$ against the corresponding overall roundness ratio and the overall aspect ratio under the vertical load of $400 \mathrm{kPa}$. The relationships between the roundness, the aspect ratio and
Fig. 9 Roundness against shear strain under vertical loading stress of $400 \mathrm{kPa}$

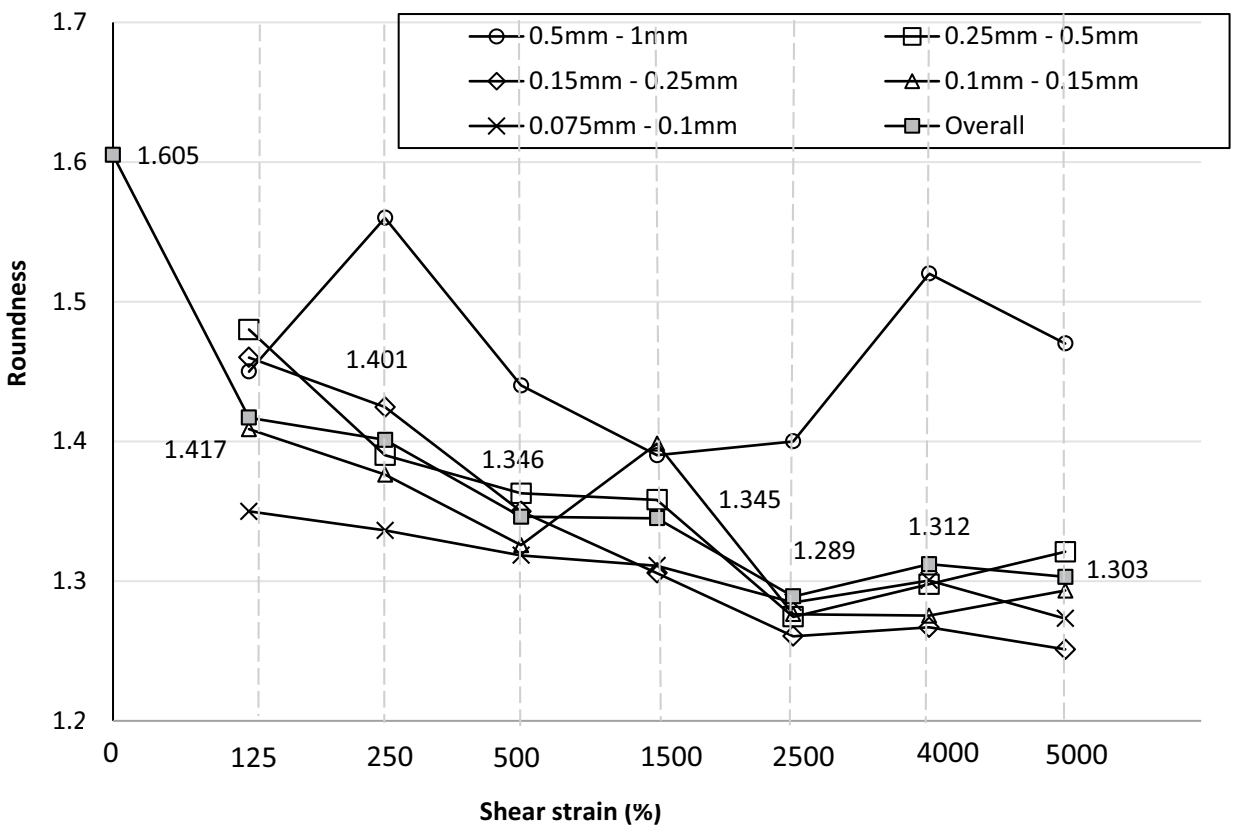


Fig. 10 Aspect ratio against shear strain under vertical loading stress of $400 \mathrm{kPa}$

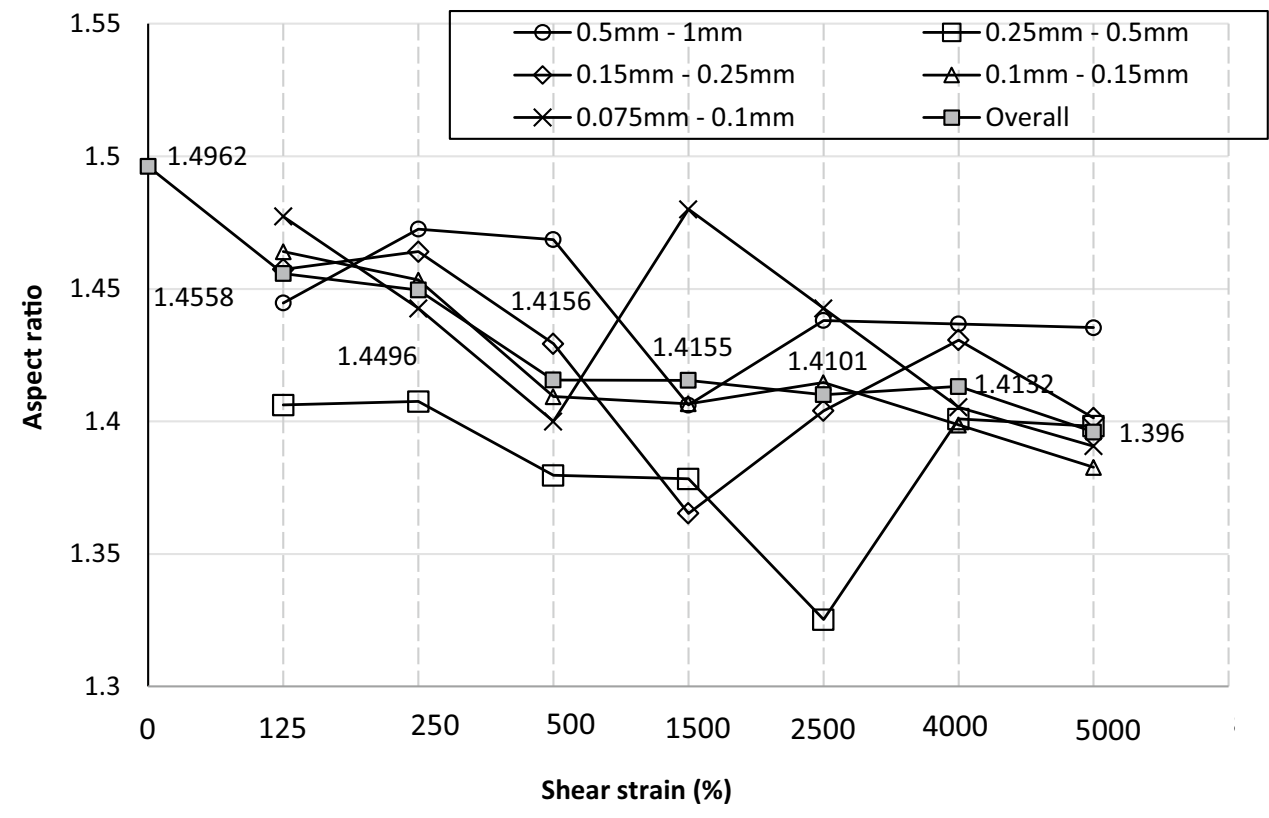

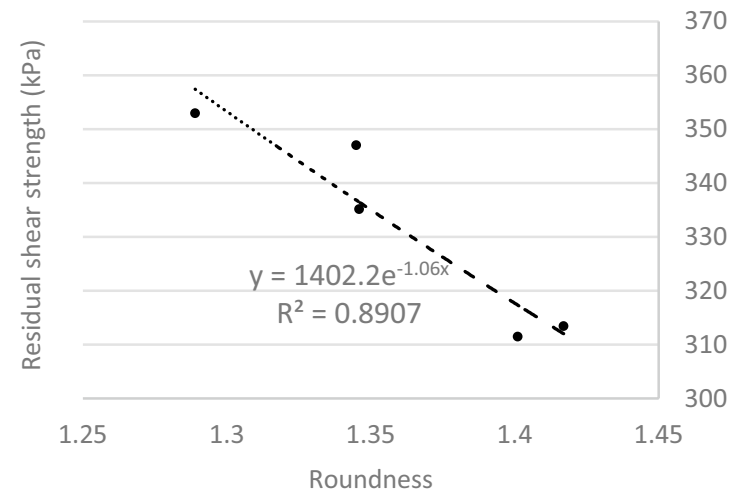

(a)

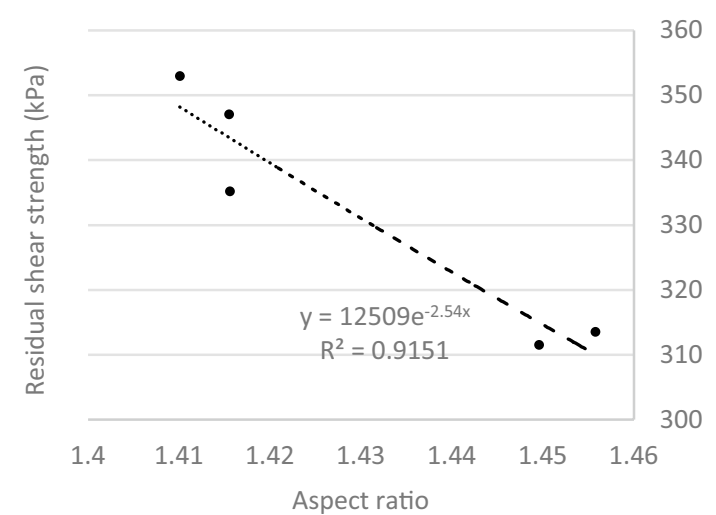

(b)

Fig. 11 Residual shear strength against: a roundness; $\mathbf{b}$ aspect ratio

the residual shear strength fit well by an inverse correlation. The residual shear strength decreased with increasing roundness and aspect ratio, which illustrated the strong effect of particle breakage on the residual shear strength.

\section{Discussion}

The dynamic fragmentation induced micro-structure change of calcareous sands could be illustrated by the Scanning Electron Microscopy (SEM) images, as shown in Fig. 12. In this figure, calcareous sands were under vertical loading stress of $400 \mathrm{kPa}$. It is shown that the particles had angular shape with porous structures at the shear strain of $125 \%$. When the shear strain reached $2500 \%$, the previous void space disappeared, because the porous structures were crushed induced by long distance of shearing and the void space was filled with fine particles highlighted by the red circle. Because these fine particles effectively filled up the void space, calcareous sand structures showed relatively smooth surfaces. This process of particle breakage is illustrated in Fig. 13. During the shear test, some of the particle skeletons were broken and some new skeletons were formed. At the same time, fine calcareous sand particles fell into the void spaces, cushioning and protecting new calcareous sand skeletons from further brakeage. With the increase of the shear strain, this process was repeated. Coarse calcareous particles were continuously cut and crushed, and hence the aspect ratio is continuously reduced. 
Fig. 12 Images of calcareous sand at the shear strain of a $125 \%$ and b $2500 \%$

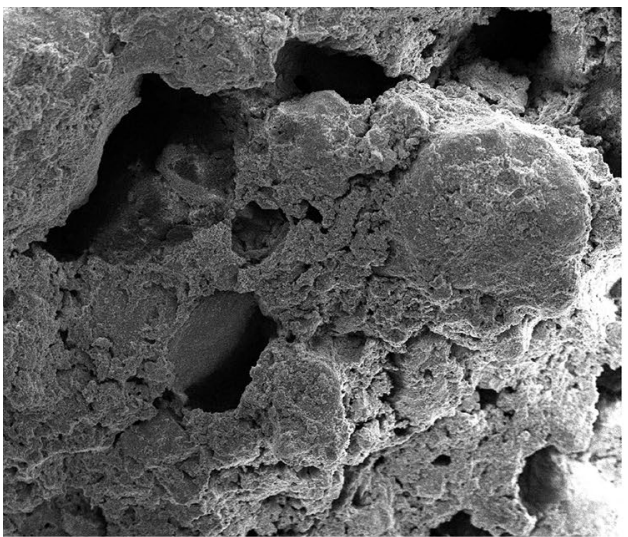

(a)

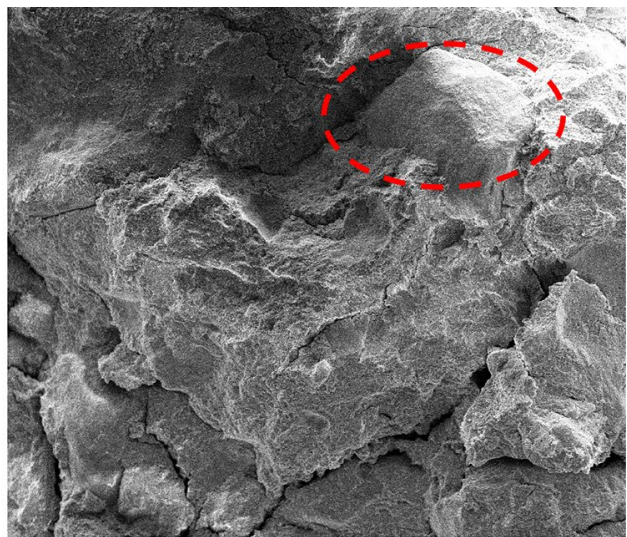

(b)

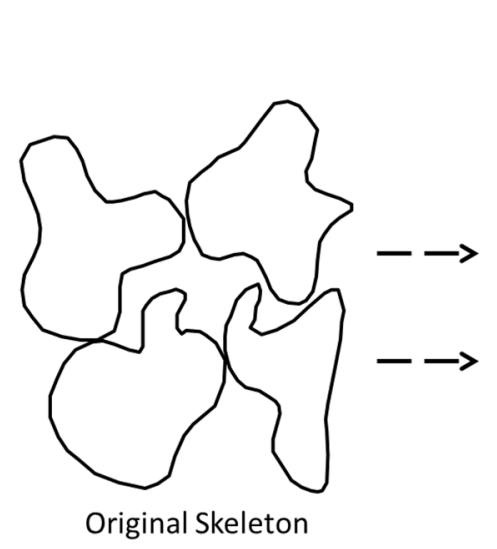

(a)
Fine Particles

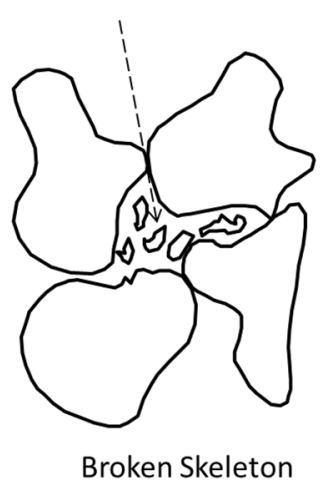

(b)
Fig. 13 Concept of particle breakage during shear test: a before shearing; $\mathbf{b}$ after shearing

The relationship between particle breakage and the change in shear strength of calcareous sands is illustrated in Fig. 14. At the beginning of shearing, a large amount of calcareous sand particles were intact with irregular shapes. Therefore the contacts between the calcareous sand particles became tighter and tighter. Accordingly, the dilatancy and particles interlocking of calcareous sand appeared, generating the peak shear strength, as shown in Fig. 14a. In the post-peak stage, large quantity of calcareous sand particles began to rupture, which eliminated the previous close interparticle contacts. Hence, the shear strength reduced significantly at this stage (Fig. 14b). Then after the large displacement of shearing, the particles began to be re-arranged and the new contacts and particles interlocking developed. At the same time, the calcareous sand particles formed new micro-structures. During this rearrangement process, the peak shear strength induced by irregular coarse sand particles was gradually replaced by the residual shear strength induced by weak and fine sand particles (Fig. 14c and d).
With shear displacement increases, more and more fine particles filled in void spaces and the interparticle contacts and interlocking were continually strengthened. This process made the residual shear strength increase continuously and slowly. On the other hand, some of the new interlocking could not withstand the external loading and failed again. The repeated process generated the fluctuation in the shear stress-displacement curve. It can be seen that the mechanism of shear strength varied, which resulted in the peak shear strength of the calcareous sand much larger than the other two, and the initial residual strength the smallest.

\section{Conclusion}

In this study, the Scanning Electron Microscopy was used to quantify the particle breakage of calcareous sands during the ring shear test. Accordingly, some conceptual models were proposed to explain the effect of particle breakage on the change in shear strength by investigating the mechanical properties, fracture characteristics and particle shape characteristics of calcareous sands, and the following main conclusions have been obtained:

(1) At the beginning of shearing, both the roundness and aspect ratio of the calcareous sand particles reduced significantly, so surfaces of the particles tended to be smooth and rounded. On the other hand, after the shear strain reached $4000 \%$, the changes in the roundness and aspect ratio became very limited, which indicated there was no further particle breakage occurring during this stage.

(2) The residual shear strength decreased with increasing roundness and aspect ratio due to the effect of particle breakage on the residual shear strength. 


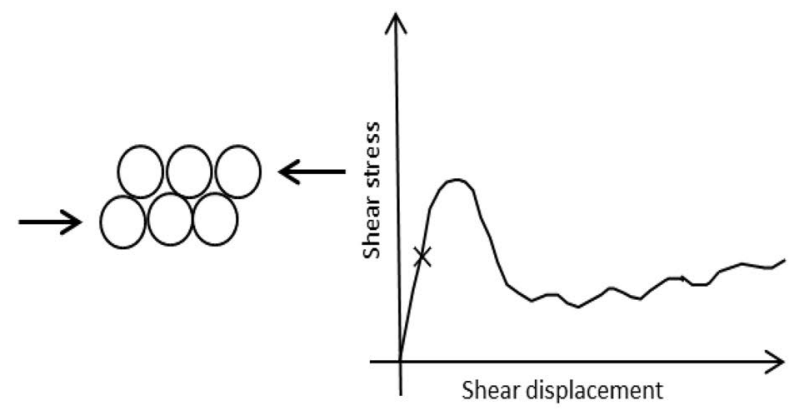

(a)
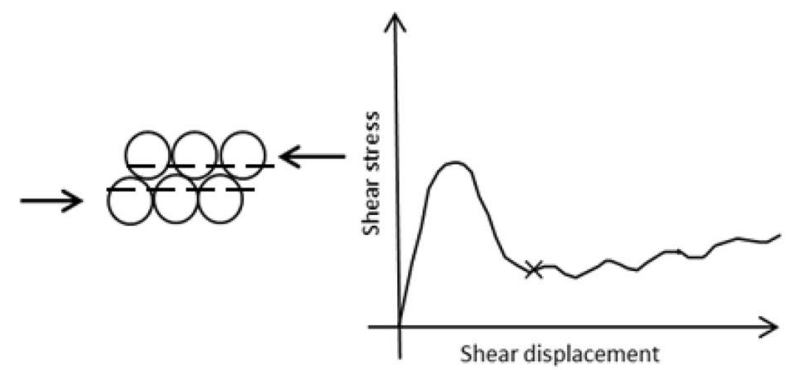

(c)

Fig. 14 Effect of particle breakage at different stages of ring shear test

(3) At the same shear strain, the roundness and aspect ratio of the particles decreased as the vertical loading stress increased. This is because large vertical loading stress made the particle breakage easier.

(4) After analysing the mechanism of the particle breakage, a simple concept model of the shear strength has been established. The strength depended on the smoothness of the particles surface and the number of particle contacts. Particles with a high value of roundness resulted in stronger interparticle contacts and more interlocking. The maximum value of interlocking appeared when shear strength reached the peak value. Once particles started to break the effect of interlocking would be reduced. As the shear displacement increased, particles tend to rearrange and form new interparticle contacts and interlocking, generating an increase in the final residual shear strength.

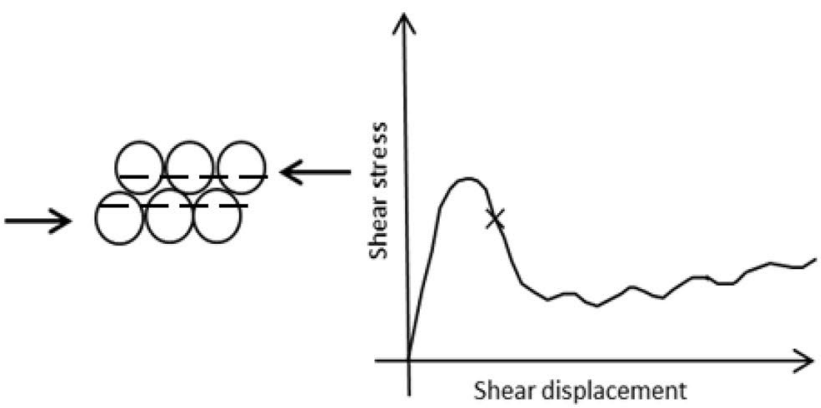

(b)

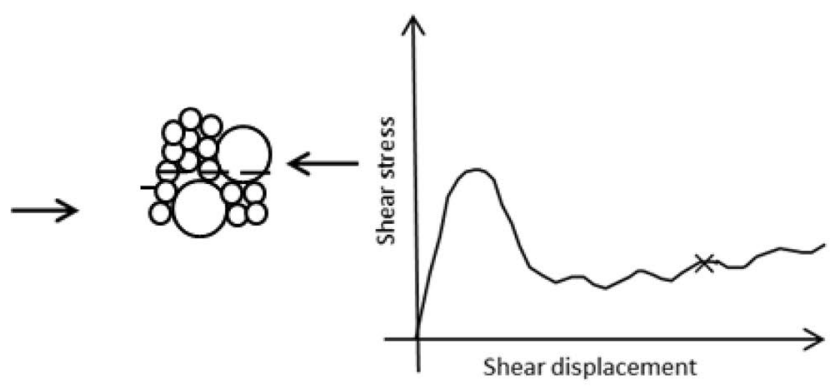

(d)

Acknowledgements This research was supported by the Strategic Priority Research Program of the Chinese Academy of Sciences (Grant No. XDA19060301), and the National Natural Science Foundation of China (Grant Nos. 41877260 and 41772336). All the support is acknowledged.

Open Access This article is licensed under a Creative Commons Attribution 4.0 International License, which permits use, sharing, adaptation, distribution and reproduction in any medium or format, as long as you give appropriate credit to the original author(s) and the source, provide a link to the Creative Commons licence, and indicate if changes were made. The images or other third party material in this article are included in the article's Creative Commons licence, unless indicated otherwise in a credit line to the material. If material is not included in the article's Creative Commons licence and your intended use is not permitted by statutory regulation or exceeds the permitted use, you will need to obtain permission directly from the copyright holder. To view a copy of this licence, visit http://creativecommons.org/licenses/by/4.0/. 


\section{References}

Altuhafi FN, Coop MR (2011) Changes to particle characteristics associated with the compression of sands. Géotechnique 61(6):459-471

Bolton MD, Nakata Y, Cheng YP (2008) Micro- and macro-mechanical behaviour of DEM crushable materials. Géotechnique 58(6):471-480

Coop MR, Atkinson JH (1993) The mechanics of cemented carbonate sands. Géotechnique 43(1):53-67

Coop MR, Sorensen KK, Freitas TB, Georgoutsos G (2004) Particle breakage during shearing of a carbonate sand. Géotechnique 54(3):157-163

Cox MR, Budhu M (2008) A practical approach to grain shape quantification. Eng Geol 96(1-2):1-16

David WA, John PC, Martin DL (2011) Sydney soil model. II: experimental validation. Int J Geomech 11(3):225-238

Einav I (2007) Breakage mechanics—part I: theory. J Mech Phys Solids 55(6):1274-1297

Fukuoka H, Sassa K, Wang G (2007) Shear behavior and shear zone structure of granular materials in naturally drained ring shear tests. In: Sassa K, Fukuoka H, Wang F, Wang G (eds) Progress in landslide science. Springer, Berlin, Heidelberg, pp 99-111

Hardin BO (1985) Crushing of soil particles. J Geotech Eng 111(10):1177-1192

Hentschel ML, Page NW (2003) Selection of descriptors for particle shape characterization. Part Part Syst Charact 20(1):25-38

Hyodo M, Hyde AFL, Aramaki N, Nakata Y (2002) Undrained monotonic and cyclic shear 405 behaviour of sand under low and high confining stresses. Soils Found 42(3):63-76

Kong D, Fonseca J (2018) Quantification of the morphology of shelly carbonate sands using 3D images. Géotechnique 68(3):249-261

Lade P, Yamamuro J, Bopp P (1996) Significance of particle crushing in granular materials. J Geotech Eng 122(4):309-316

Merkus HG (2009) Particle size measurements: fundamentals, practice, quality, vol. 17. Springer Science \& Business Media, pp 14-16

Miao G, Airey D (2013) Breakage and ultimate states for a carbonate sand. Géotechnique 63(14):1221-1229
Olson E (2011) Particle shape factors and their use in image analysis part 1: theory. J GXP Compliance 15(3):85

Pfleiderer S, Klein P, Reitner H, Heinrich M (2006) The hydrogeology of the northern calcareous Alps between the rivers Enns and Ybbs. Int J Aust Geol Soc 99:4-10

Shahnazari H, Rezvani R (2013) Effective parameters for the particle breakage of calcareous sands: an experimental study. Eng Geol 159:98-105

Wang X-Z, Wang X, Jin Z-C, Meng Q-S, Zhu C-Q, Wang R (2017) Shear characteristics of calcareous gravelly soil. Bull Eng Geol Environ 76(2):561-573

Wei H, Zhao T, He J, Meng Q, Wang X (2018) Evolution of particle breakage for calcareous sands during ring shear tests. Int $\mathrm{J}$ Geomech 18(2):04017153

Wu Y, Yoshimoto N, Hyodo M, Nakata Y (2014) Evaluation of crushing stress at critical state of granulated coal ash in triaxial test. Géotech Lett 4(4):337-342

Xu D, Liu Q, Qin Y, Chen B (2020a) Analytical approach for crack identification of glass fiber reinforced polymer-sea sand concrete composite structures based on strain dissipations. Struct Health Monit 1475921720974290

Xu DS, Huang M, Zhou Y (2020b) One-dimensional compression behavior of calcareous sand and marine clay mixtures. Int $\mathbf{J}$ Geomech 20(9):04020137

Xu DS, Xu XY, Li W, Fatahi B (2020c) Field experiments on laterally loaded piles for an offshore wind farm. Marine Struct 69:102684

Yu FW (2017) Particle breakage and the drained shear behavior of sands. Int J Geomech 17(8):04017041

Zhang S, Tong C-X, Li X, Sheng D (2015) A new method for studying the evolution of particle breakage. Géotechnique 65(11):911-922

Publisher's Note Springer Nature remains neutral with regard to jurisdictional claims in published maps and institutional affiliations. 